\title{
Aplikasi Reminder Kontrak Kerja di PT. Rejeki Perdana Makmur
}

\author{
Widyo Ari Utomo*1, Ernes Cahyo Nugroho ${ }^{2}$, Christian Bimantara Nakula Alphade o ${ }^{3}$, \\ Sidik Purnomo ${ }^{4}$ \\ 1,2,3,4Program Studi Sistem Komputer, STMIK AUB, Surakarta, Indonesia \\ e-mail: ${ }^{* 1}$ widyoari@stmik-aub.ac.id, ${ }^{2}$ ernes.cahyo@stmik-aub.ac.id
}

\begin{abstract}
Abstrak
PT. Rejeki Perdana Makmur merupakan salah satu bengkel mobil yang sedang berkembang di surakarta. Menejemen karyawan yang dimiliki PT. Rej eki Perdana Makmur masih dilakukan dengan cara mengisi formulir karyawan lalu menatanya di rak dokumen yang dinilai kurang maksimal dalam mengecek lama durasi kontrak karyawan. Selain itu dalam hal keamanan PT. Rejeki Perdana Makmur masih memiliki kelemahan yaitu berkas formulir data karyawan dapat hilang atau terselip.

Oleh karena itu dibuat Aplikasi Reminder Kontrak Kerja Karyawan berbasis aplikasi desktop di PT. Rejeki Perdana Makmur. Sistem ini dibangun dengan menggunakan metode DFD, Flowchart dan Contex Diagram, dibuat berbasis desktop menggunakan bahasa pemrograman VB.net, database MySQL, dan Xampp. Aplikasi ini dapat mengolah data produk dan menampilkan informasi lama durasi kontrakkaryawan, tanggal berakhir kontrak karyawan dan data data pendukungnya.Aplikasi yang dibangun telah membantu pihak ben gkel dalam memenejemen durasi kontrak kerja karyawan yang ada di bengkel PT. Rejeki Perdana Makmur Surakarta.
\end{abstract}

Kata kunci-Desktop, Reminder, Rejeki Perdana Makmur, Xampp, MySQL, VB.net,

\begin{abstract}
PT. Rejeki Perdana Makmur is one of the developing car workshop in surakarta. Management of employees owned by PT. Rejeki Perdana Makmur is still done by filling out the employee form and arrange on the shelves of documents that are considered less than the maximum in checking the duration of employee contracts. In addition, in terms of se curity PT. Rejeki Perdana Makmur still has weaknesses that file employee data form can be lost or tucked.

Therefore created Application Employee Contract Employment Contract Reminder based on PT. Rejeki Perdana Makmur. The system is built using DFD, Flowchart and Contex Diagram methods, based on desktop using VB.net, MySQL, and Xampp. This application can process product data and display information duration of employee contract, expiration date of employee contract and data of supporter data. The application that was built has helped the workshop in memenejemen duration of employment contract employee in workshop of PT. Rejeki Perdana Makmur Surakarta.
\end{abstract}

Keywords-Desktop, Reminder, Rejeki Perdana Makmur, Xampp, MySQL, VB.net.

\section{PENDAHULUAN}

PT. Rejeki Perdana Makmur adalah perusahaan yang bergerak dalam bidang usaha jasa bengkel mobil yang memiliki banyak karyawan. Dengan besarnya jumlah karyawan yang dimiliki, PT. Rejeki Perdana Makmur harus memiliki sistem basis data yang mampu 
menyimpan berbagai macam informasi didalam perusahaan yang mereka miliki khususnya mengenai data karyawan. Dimana dalam perkembangan bidang tenaga kerja masyarakat Indonesia sistem kontrak kerja menjadi suatu kebutuhan untuk mempermudah dalam memenejemen dan memonitoring status kerja karyawan suatu perusahaan, sehingga apabila terdapat kontrak kerja yang hampir habis dapat langsung memberikan pemberitahuan secara real time kepada menejemen perusahaan.

Perjanjian kerja adalah perjanjian antara pekerja/buruh dengan pengusaha atau pemberi kerja. Perjanjian tersebut memuat syarat-syarat kerja, hak, dan kewajiban para pihak. Hubungan kerja adalah hubungan antara pengusaha dengan pekerja/buruh berdasarkan perjanjian kerja, yang mempunyai unsur pekerjaan (yang harus dikerjakan pekerja/buruh), upah, dan perintah (yang harus dilaksanakan pekerja/buruh).

Kontrak kerja dapat berupa lisan atau tulisan, dan didasari oleh kesepakatan bersama. Perjanjian kerja dapat memiliki jangka waktu tertentu (PKWT) atau jangka waktu tidak tertentu (PKWTT) memiliki syarat kesepakatan kedua belah pihak, kecakapan para pihak melakukan perbuatan hukum, adanya pekerjaan yang diperjanjikan, dan pekerjaan yang diperjanjikan tidak bertentangan dengan ketertiban umum, kesusilaan, dan peraturan perundang undangan yang berlaku. Apabila tidak memenuhi semua persyaratan tersebut, maka perjanjian kerja dianggap tidak sah dan batal demi hukum.Saat ini di PT. Rejeki Perdana Makmur dalam melakukan pencatatan data-data karyawan masih mengunakan buku dan dokumen office seperti Microsoft Word dan Excel yang selama ini di gunakan. Untuk mengelola berbagai data karyawan yang berhubungan dengan kontrak kerja. Pengelolaan data seperti ini memiliki banyak kekurangan seperti duplikasi data,hilangnya data, kerusakan data, dan kesalahan dalam memasukan data.

Dengan memanfaatkan teknologi, saat ini banyak diciptakan aplikasi Pengingat yang dapat mendukung berbagai kegiatan didalam perusahaan salah satunya untuk mengelola data kontrak kerja. Aplikasi reminder adalah salah satu solusi untuk mengatasi masalah yang terjadi PT. Rejeki Perdana Makmur yang banyak memiliki karyawan,dimana dengan adanya aplikasi ini,bagian menejemen dengan mudah dalam memenejemen dan memonitoring status kerja karyawan, sehingga apabila terdapat kontrak kerja yang hampir habis dapat langsung memberikan pemberitahuan secara real time kepada menejemen perusahaan.

Hal ini mendorong kami melakukan Kerja Praktek Perancangan dan Implementasi Sistem di PT. Rejeki Perdana Makmur, yaitu merancang dan mengimplementasikan sistem reminder kontrak kerja agar mampu memberikan informasi yang lengkap dan akurat bagi Human Resources Development (HRD) dan karyawan. Bertujuan untuk memonitoring data-data kontrak kerja berdasarkan periode kontrak pekerja dan meningkatkan pelayanan kepada pelanggan. Dengan ini peneliti mengambil judul untuk KPPIS yaitu "Aplikasi Reminder Kerja Di PT. Rejeki Perdana Makmur".

\section{METODE PENELITIAN}

\subsection{Aplikasi Reminder kontrak kerja di PT. Rejeki Perdana Makmur}

2.1.1 Sistem Reminder kontrak kerja di PT. Rejeki Perdana Makmur yang sedang berjalan

Sistem Reminder kontrak kerja di PT. Rejeki Perdana Makmur yang berjalan selama ini masih menggunakan buku dan dokumen office seperti Microsoft Word dan Excel untuk mengelola berbagai data karyawan yang berhubungan dengan kontrak kerja. Pengelolaan data seperti ini memiliki banyak kekurangan seperti duplikasi data hilangnya data, kerusakan data, dan kesalahan dalam memasukan data. Hal inilah yang sering membuat petugas membutuhkan waktu yang lama dalam mencatat dan mengecek data kontrak karyawan, karena masih dicatat secara tertulis mengunakan form kertas yang selanjutnya di simpan dalam sebuah stopmap. Flowchart sistem yang berjalan dapat dilihat pada Gambar 1. 


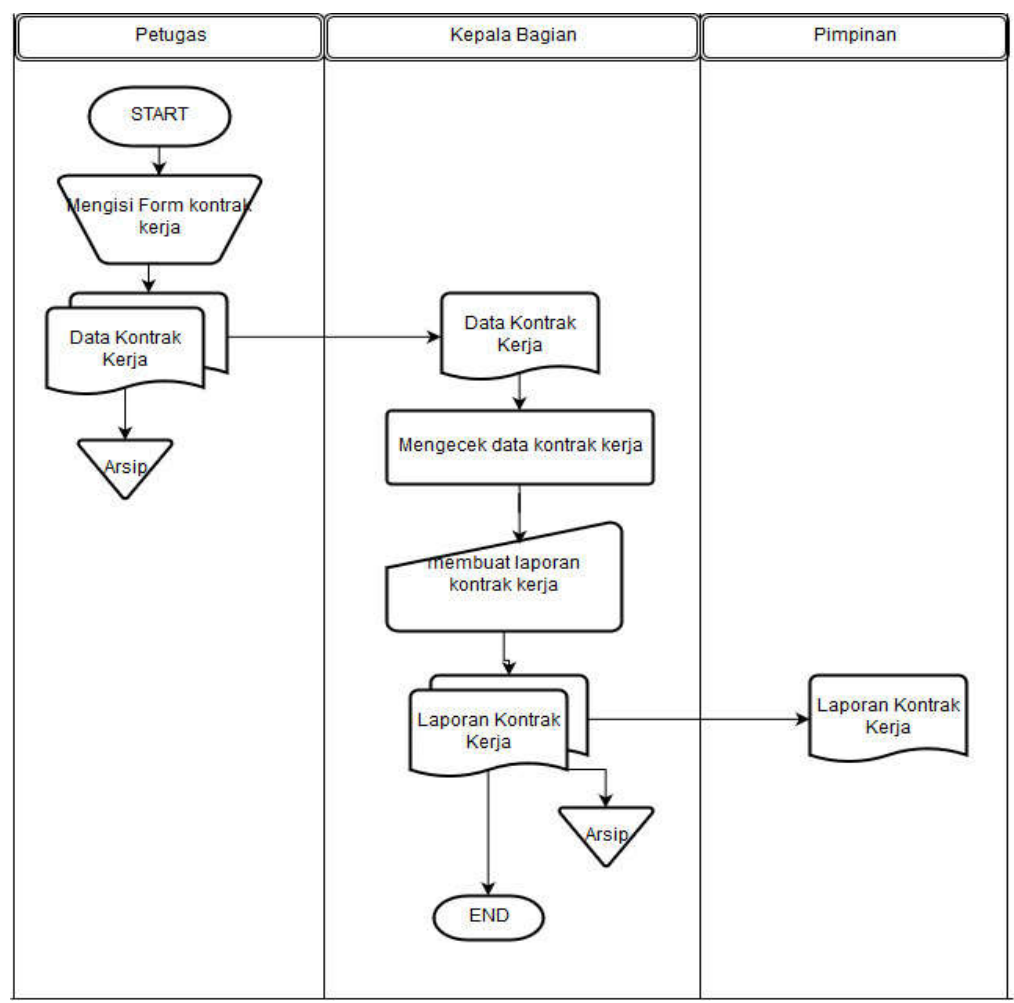

Gambar 1 Flowchart Sistem yang sedang berjalan

\subsubsection{Aplikasi reminder kontrak kerja di PT. Rejeki Perdana Makmuryang akan dibangun}

Aplikasi pengingat kontrak kerja yang akan dibangun merupakan otomatisasi terhadap proses pengelolaan durasi kontrak kerja karyawan di PT. Rejeki Perdana Makmur. Sistem yang baru ini akan dibangun menggunakan sistem yang berjalan dengan menggunakan sistem desktop yang mendukung sistem informasi pengelolaan database menggunakan MySQL.

Sistem pengelolaan durasi kontrak kerja karyawan yang baru bertujuan untuk memberikan kemudahan pada bagian Human Resources Development PT. Rejeki Perdana Makmur dalam mengelola data durasi kontrak kerja karyawan yang ada. Adapun flowchart sistem yang diusulkan ke kantor PT. Rejeki Perdana Makmur Surakarta dapat di lihat pada Gambar 2. 


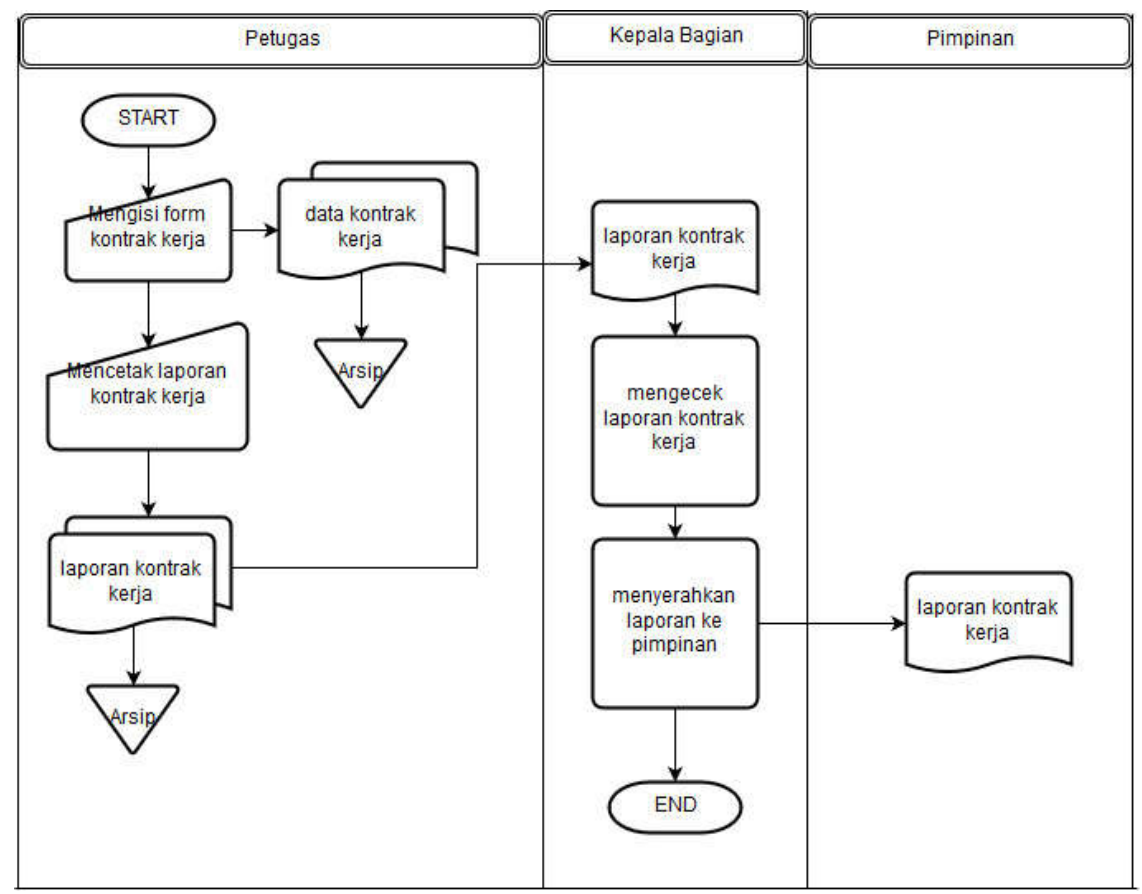

Gambar 2 Flowchart Sistem yang Diusulkan

\subsection{Fungsi dan Kegunaan Aplikasi Reminder}

a. Fungsi Sistem

1. Meringankan kerja petugas

2. Mempermudah pembuatan laporan

3. Sebagai pengigat kontrak kerja karyawan

b. Manfaat Sistem

1. Menginput otomatisasi kode karyawan yang ada.

2. Memberikan hak akses kepada bagian HRD untuk pengelolaan durasi kontrak kerja karyawan.

3. Melakukan penyimpanan semua data durasi kontrak kerja karyawan.

4. Melakukan penambahan dan pengurangan data karyawan dengan cepat.

5. Memberikan informasi laporan durasi kontrak kerja karyawan dengan cepat.

\subsubsection{Cara Kerja Sistem}

Sistem Reminder kontrak karyawan di PT. Rejeki Perdana Makmur berisi sebagai berikut :

a. Data format kode karyawan;

b. Data nama karyawan, nomor ktp, bagian, jaminan kerja dan durasi kontrak ;

c. Data karyawan yang akan habis masa kontraknya ;

d. Data karyawan yang sudah habis masa kontraknya ;

e. Laporan data durasi kontrak kerja karyawan.

Penjelasan mengenai cara kerja Aplikasi Pengingat Kontrak Karyawan yang baru adalah sebagai berikut:

a. Pada halaman utama terdapat dua tombol yakni karyawan dan cetak laporan.

b. Petugas menggeklik tombol karyawan akan masuk ke data karyawan apabila ingin merubah dan menghapus data karyawan. Pada data karyawan petugas bisa menambah kontrak karyawan baru dan menggecek data karyawan yang sudah habis atau belum massa kontraknya.

c. Pada form kontrak karyawan,petugas mengimputkan kode, nama, nomor ktp, jaminan kerja, bagian, tanggal masuk dan lama kontrak untuk menambah karyawan yang akan melakukan kontrak kerja. Pada form kontrak karyawan juga terdapat tombol simpan dan hapus. 
d. Pada form cek petugas dapat mengetahui data karyawan yang sudah habis atau mendekati masa kontraknya.

e. Petugas pada tombol cetak laporan,petugas dapat mencetak laporan karyawan aktif, karyawan yang sudah mengalami masa tenggang dan karyawan yang telah habis masa kontraknya atau sudah non-aktif.

\subsection{Perancangan Sistem}

Perancangan sistem adalah tahap setelah analisis dan siklus pengembangan sistem dari kebutuhan-kebutuhan fungsional dan persiapan untuk rancangan bangun implementasi bagaimana suatu sistem dibentuk.

\subsubsection{Perancangan Proses}

Perancangan Proses yang digunakan untuk menggambarkan bagaimana sistem berjalan dan bertujuan untuk membangun sebuah sistem yang dapat memenuhi kebutuhan dan tujuan yang ingin dicapai. Dalam hal perancangan proses akan digambarkan dengan Context Diagram, DFD level 0,dan DFD level 1.

a. Context Diagram

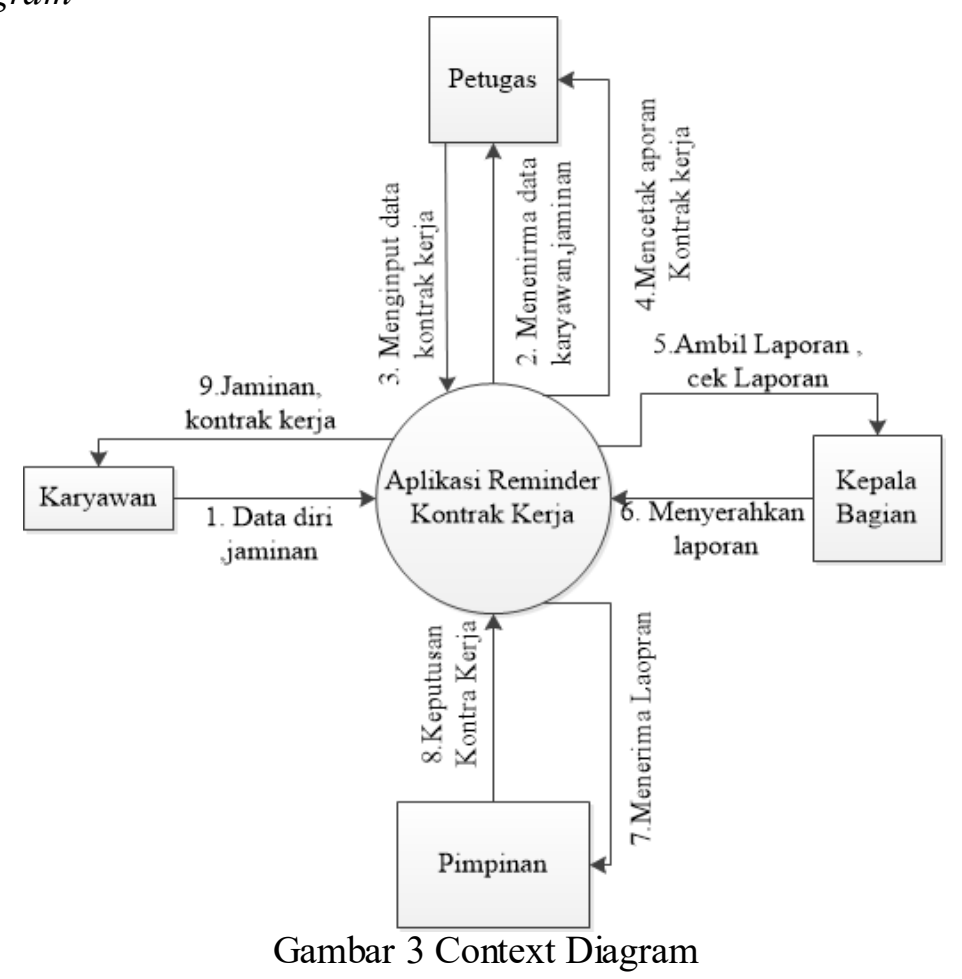

b. DFD lvl 0 


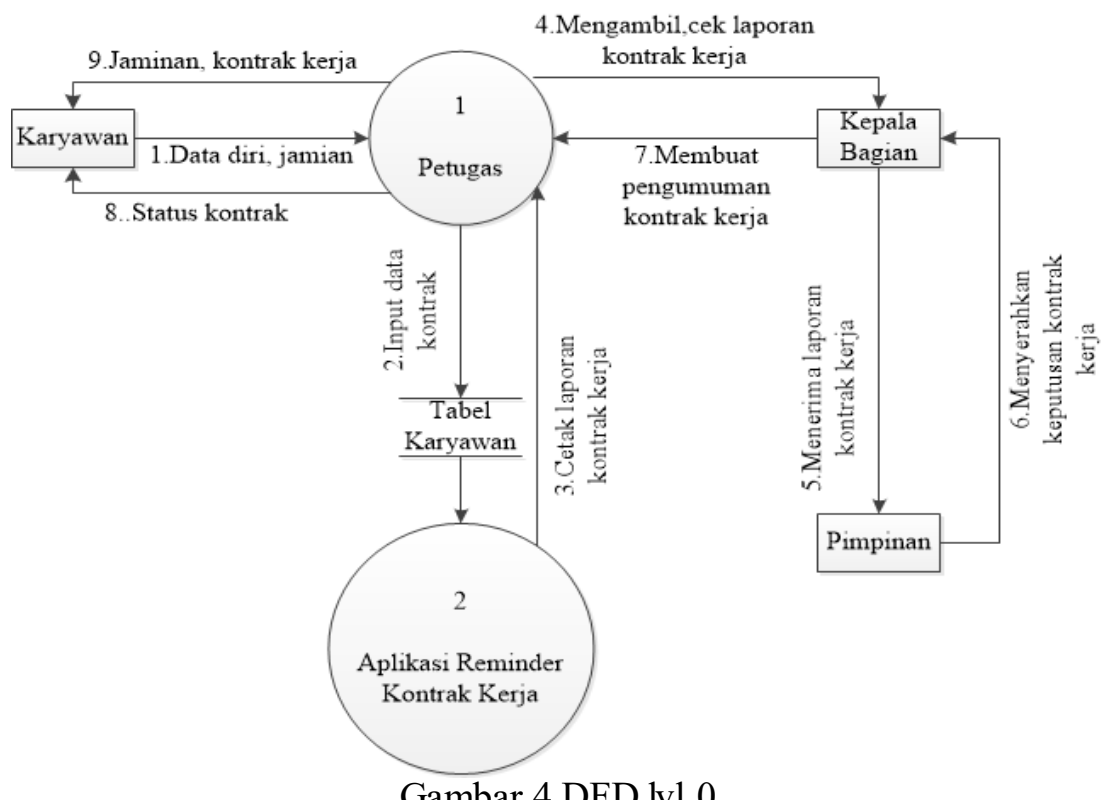

c. DFD lvl 1.1 Petugas

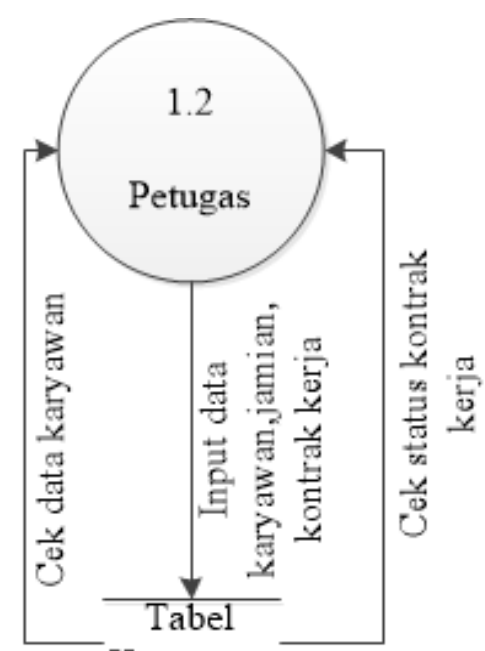

Karyawan

Gambar 5 DFD lvl 1.1 Petugas

d. DFD lv1 2.1 Aplikasi Reminder Kontrak Kerja

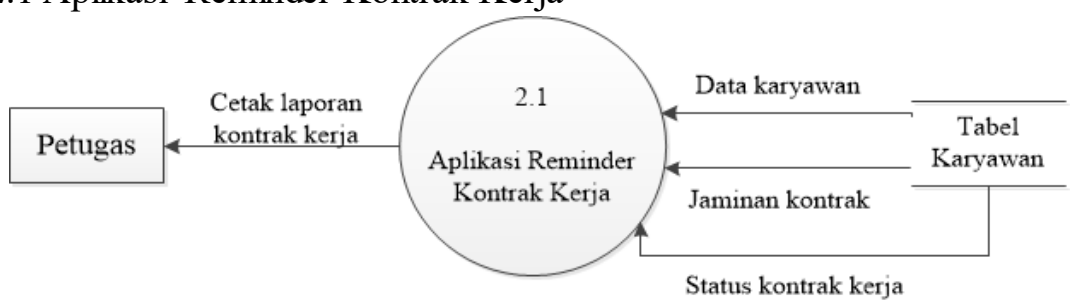

Gambar 6 DFD lv1 2.1 Aplikasi Reminder Kontrak Kerja

2.4 Kelemahan dan Keunggulan Sistem

2.4.1 Analisa Sistem

Analisa dan perancangan sistem yang dilakukan, menggunakan pendekatan berbasis proses (proses oriented approach) dengan model proses yang digunakan adalah Waterfall 
Model. Model ini adalah model klasif yang bersifat sistematis, berurutan dalam membangun perangkat lunak. Tahapan yang dilakukan dalam membangun sistem ini adalah :

a. Analisa kebutuhan

Analisa kebutuhan merupakan tahap pertama yang menjadi dasar proses pembuatan software selanjutnya. Untuk memperoleh informasi tentang proses bisnis dan kebutuhan perusahaan, umumnya melakukan wawancara, diskusi dan survey.

b. Desain sistem

Desain sistem merupakan tahap penyusunan proses, data, aliran proses dan hubungan antar data yang paling optimal untuk menjalankan proses bisnis dan memenuhi kebutuhan perusahaan sesuai dengan hasil analisa kebutuhan. Dokumentasi yang dihasilkan dari tahap desain sistem ini antara lain : $U M L$ dan sebagainya.

c. Penulisan kode program

Penulisan kode program merupakan tahap penerjemahan desain sistem yang telah dibuat ke dalam bentuk perintah-perintah yang dimengerti komputer dengan mempergunakan bahasa pemrograman.

d. Pengujian program

Pengujian software dilakukan untuk memastikan bahwa software yang dibuat telah sesuai dengan desainnya dan semua fungsi dapat dipergunakan dengan baik tanpa ada kesalahan.

e. Penerapan program

Penerapan program merupakan dimana menerapkan atau meng-install software yang telah selesai dibuat dan diuji ke dalam perusahaan dan memberikan pelatihan kepada pengguna di perusahaan.

\section{HASIL DAN PEMBAHASAN}

\subsection{Impementasi Sistem}

Implementasi adalah salah satu cara mengoperasikan sistem informasi yang telah dibuat. Berikut aplikasi reminder kontrak kerja karyawan.

\subsubsection{Halaman Utama}

Pada halaman utama aplikasi reminder kontrak kerja terdapat logo perusahaan dan tombol yang terhubung dengan tabel data karyawan dan cek laporan. Desain halaman utama dapat di lihat pada Gambar 7 halaman utama.

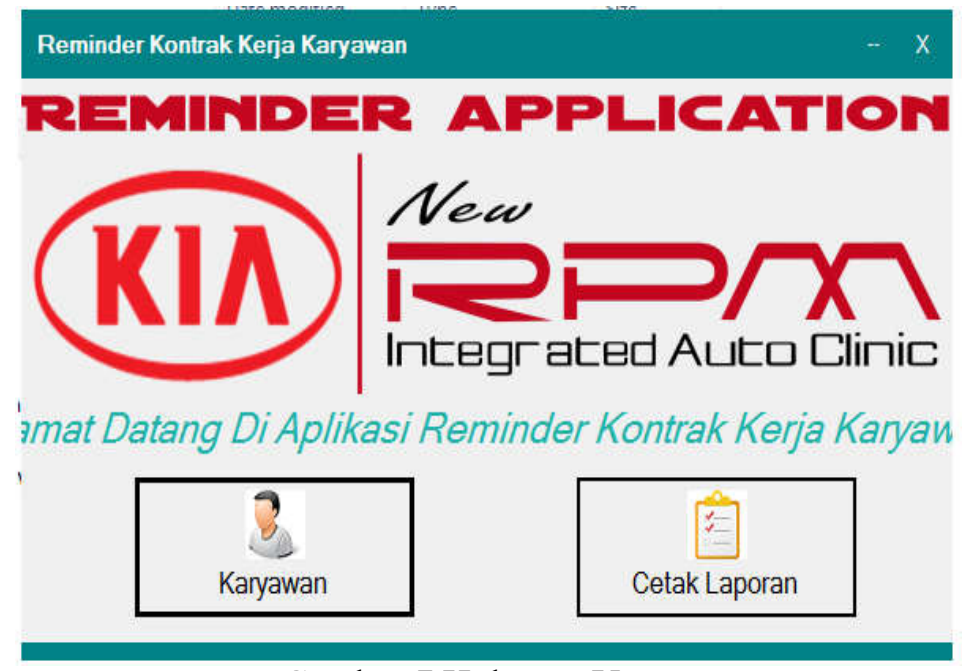

Gambar 7 Halaman Utama

\subsubsection{Data Karyawan}

Pada data karyawan terdapat 5 (lima) button yang dapat digunakan yaitu cari, edit, hapus, kontrak karyawan dan cek. Pada halaman utama ini menampilkan data karyawan yang 
melakukan kontrak kerja di PT. Rejeki Perdana Makmur.Data tersebut seperti kode, nama, nomor ktp, jaminan kerja, status, tanggal masuk, lama kontrak. Desain dari menu utama dapat dilihat dari Gambar 8 Gambar Form Data Karyawan.

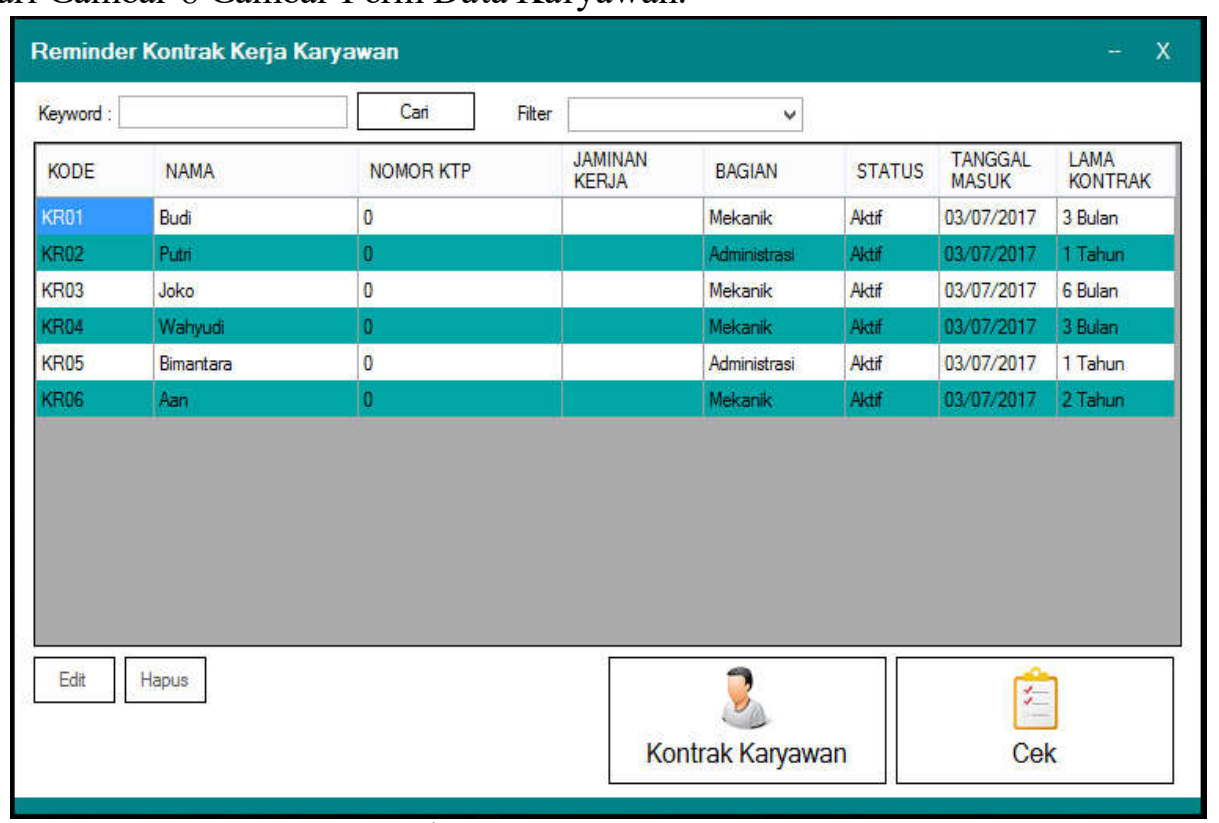

Gambar 8 Form Data Karyawan

Berikut fungsi button yang berada pada data karyawan:

a. Cari

Pada tombol cari diguanakan untuk menemukan data dengan memasukan kata kunci seperti kode atau nama karyawa lalu menekan tombol cari.

b. Edit

Tombol edit untuk mengubah atau menambah data kontrak kerja.

c. Hapus

Tombol hapus berguana untuk menghapus data karyawan yang salah atau menghapus data karyawan yang sudah tidak lagi bekerja di PT. Rejeki Perdana Makmur.

d. Kontrak Karyawan

Pada tombol kontrak karyawan akan di hubungkan dengan form karyawan. Pada form karyawan, user di haruskan mengisi data karyawan yang akan melakukan kontrak kerja seperti kode, nama, nomor ktp, jaminan kerja, bagian, tanggal masuk, kontrak. Setelah data tersebut di isi dan di simpan akan di tampilkan pada halaman utama. Form karyawan dapat dilihat pada Gambar 9 desain form karyawan. 


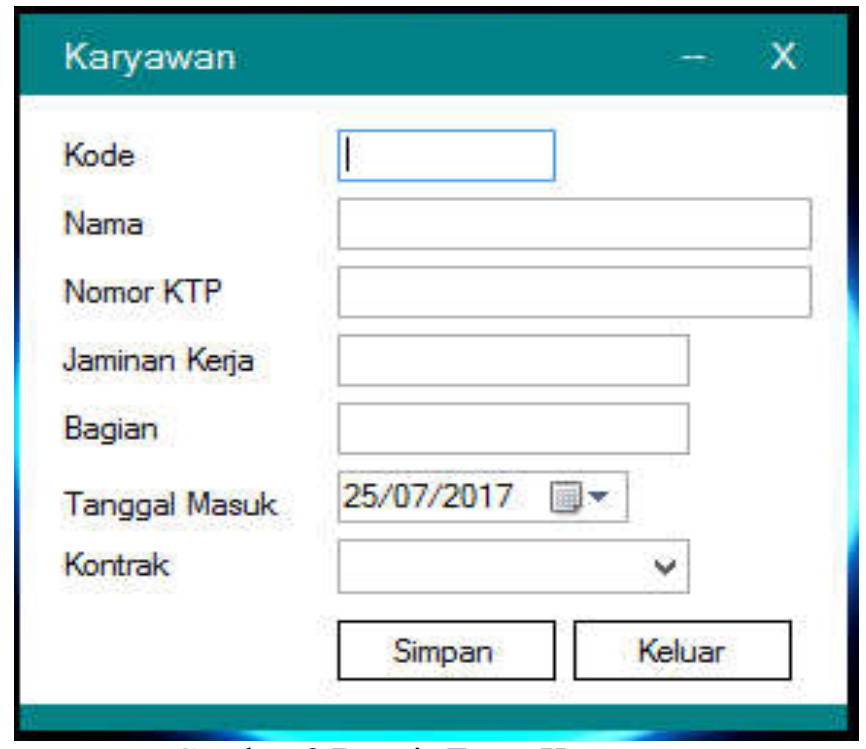

e. Cek

\section{Gambar 9 Desain Form Karyawan}

Pada tombol cek berisi notifikasi pegawai yang sudah mengalami habis masa kontrak kerjanya. Desing notifikasi karyawan bisa di lihat pada Gambar 10 Notifikasi pegawai

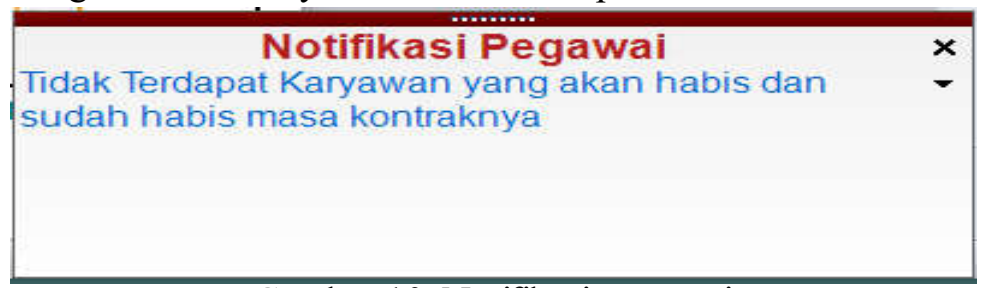

Gambar 10 Notifikasi pegawai

\subsection{Pemeliharaan Sistem}

Dalam sistem Reminder Kontrak Kerja ini, pemeliharaan sistem atau perawatan perangkat lunaknya dapat di lihat pada Gambar 11 Tipe Perawatan Sistem.

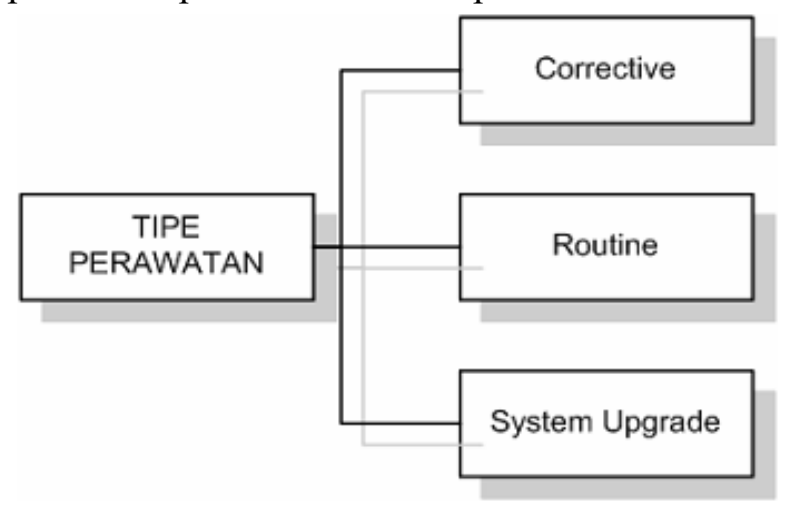

Gambar 11 Tipe Perawatan Sistem.

Penjelasan sebagai berikut :

a. Tipe perawatan corrective dilakukan jika terjadi kesalahan atau biasa dikenal sebagai bugs. Perawatan bisa dilakukan dengan memperbaiki kode program, menambah bagian yang dirasa perlu atau menghilangkan bagian-bagian tertentu.

b. Tipe perawatan routine biasa juga disebut preventive maintenance dilakukan secara rutin untuk melihat kinerja perangkat lunak ada atau tidak ada kesalahan. 
c. Tipe perawatan sistem upgrade dilakukan jika ada perubahan dari komponen-komponen yang terlibat dalam perangkat lunak tersebut. Sebagai contoh perubahan platform sistem operasi dari versi lama ke versi baru menyebabkan perangkat lunak harus diupgrade.

\section{KESIMPULAN}

Berdasarkan uraian pembahasan analisis, perancangan, implementasi sistem yang telah dilakukan pada Bengkel mobil PT. Rejeki Perdana Makmur, maka dapat disimpulkan bahwa aplikasi kontrak kerja karyawan dapat memberikan kemudahan dalam pengelolaan durasi kontrak kerja karyawan PT. Rejeki Perdana Makmur. Pengguna dapat dengan mudah melakukan pengelolaan dan pengawasan terhadap durasi kontrak yang akan habis dan yang sudah habis dengan cara lebih cepat dan efisien, sehingga mempermudah pekerjaan di bagian HRD dan mengganti cara penyimpanan data durasi kontrak kerja karyawan yang sebelumnya hanya disimpan didalam map dan rak dokumen.

\section{SARAN}

Berdasarkan perancangan sistem yang telah dibuat, maka kami mempunyai saran untuk para peneliti selanjutnya yang akan mengembangkan sistem ini, yaitu antara lain sebagai:

a. Menambahkan fungsi agar dapat berjalan di startup windows.

b. Menambahkan fungsi sudah berapa kali kontrak baru.

c. Menambahkan fungsi penggajian dan kenaikan gaji.

\section{DAFTAR PUSTAKA}

[1] Adyanata Lubis, 2016, Basis Data Dasar Untuk Mahasiswa Ilmu Komputer. Yogyakarta : Deepublish.

[2] Didik Dwi Prasetyo, 2005. Belajar Sendiri Mengolah Database den gan Visual Basic .NET dan MySQL Server. Jakarta : PT. Alex Media Komputindo.

[3] Gunawan, Imam, 2013, Metode Penelitian Kualitatif : Teoridan Praktik. Jakarta: P T. Bumi Aksara.

[4] Mohammad Nazir, 2005. Metode Penelitian. Jakarta: Ghalia Indonesia

[5] Roger S. Pressman. 2010. Waterfall Model. p.39.

[6] Sugiyono, 2013, Metode Penelitian Kuantitatif, Kualitatif, R\&D, Bandung: CV. Alfabeta.

[7] Sugiyono, 2005, Memahami Penelitian Kualitatif. Bandung: Alfabeta.

[8] Nazir, M,2005,Metode Penelitian. Jakarta: Ghalia Indonesia.

[9] Pressman RS, 2010, Software Engineering : A Practitioner's Approach, 7th ed.Mc Grow Hill

[10] Wahana Komputer, 2010. Panduan Belajar MySQL Database Server. Jakarta : Mediakita. 